\title{
DRAGGING OUT THE TRUTH: \\ RESTORATION PERIODICALS AND THE TEXTUAL CREATION OF GENDERED IDENTITIES
}

\author{
Gerd Bayer \& Jaroslaw Jasenowski \\ Friedrich-Alexander-Universität Erlangen-Nürnberg
}

\begin{abstract}
This article investigates how Restoration periodicals employed epistolary modes as a means to address their own status of fictionality. In two case studies, of John Dunton's Athenian Mercury and Peter Motteux's Gentleman's Journal, the discussion demonstrates how these periodicals make use of the supposed reliability of epistolary writing in order to undermine the truth-claims that attach to the format. In both instances, letters are employed to undermine the supposed factuality of the letter, combining such metafictional gestures with a playful and highly performative understanding of gendered identities. The gendered body of the people involved in these epistolary communications becomes a site of speculation as the letters increasingly turn into questionable bodies of reliability.
\end{abstract}

Keywords: Restoration periodicals, epistolarity, John Dunton, Athenian Mercury, Peter Motteux, Gentleman's Journal.

\author{
EXTRAYENDO VERDADES TRAVESTIDAS: \\ PERIÓDICOS DE LA ÉPOCA DE LA RESTAURACIÓN \\ Y LA CREACIÓN TEXTUAL DE IDENTIDADES DE GÉNERO
}

\section{RESUMEN}

Este artículo investiga cómo los periódicos de la Restauración utilizaron modos epistolares como medio para afrontar su propia condición de ficcional. En los dos estudios de casos, el Athenian Mercury de John Dunton y el Gentleman's Journal de Peter Motteux, el análisis demuestra que estos periódicos se apoyan en la supuesta fiabilidad de la escritura epistolar para minar la aparente veracidad asociada a este formato. En ambas publicaciones, las cartas se utilizaron para socavar la supuesta facticidad de la carta, combinando guiños metafictivos con una comprensión lúdica y altamente performativa de las identidades de género. El cuerpo (y su género) de quienes participan en estas comunicaciones epistolares resulta un espacio de especulación a medida que las cartas se van convirtiendo progresivamente en cuerpos cuestionables de fiabilidad.

Palabras clave: periódicos de la época de la Restauración, epistolaridad, John Dunton, Athenian Mercury, Peter Motteux, Gentleman's Journal.

DOI: https://doi.org/10.25145/j.recaesin.2019.79.02

Revista Canaria de Estudios Ingleses, 79; November 2019, pp. 1-31; ISSN: e-2530-8335 
Extending the broad consensus, proposed in early studies like that by Godfrey Singer and Robert Day, that the letter added to the early novel a modicum of reliability and enabled writers to represent their characters' interiority in more nuanced manners, as convincingly argued by Joe Bray, recent publications on forms of epistolary writing have instead stressed the form's deconstructive potential (Beebee), discussed the subversive element that the medium of the letter introduced to prose fiction (Schneider, Culture), and stressed the importance of epistolary culture for the formation of how individuals related to their personal and sociopolitical environment (O'Neill). The changing media environment of the English Restoration age, benefitting as it did from a more liberal attitude towards censorship and progressive legislation about copyright (Schwoerer), brought forth a substantial increase in literary culture (Hammond), including the birth of periodical and newspaper publishing on a large scale (Raymond).

It is in this cultural environment, driven by a public sphere as staged in the coffee houses (Ellis), that new forms of communication were tried out in which writers engaged in what Wolfram Schmidgen has persuasively described as the age's excitement about "exquisite mixture." The newly popularised form of the letter, both as personal form of communication and in its commercial version in print media, began to stake out its literary territory at the same time. The letter was seen as a readily available commodity, greatly supported by the recent establishment of the penny post (Whyman); yet it was also understood to be a form of communication that was easily corrupted and hence habitually used for deceptive purposes. The very principle of deception turned into a major trope within Restoration and early eighteenth-century literary culture (Loveman): there existed a general understanding within literary circles that the mediated format of epistolary communication lent itself perfectly to the kind of cultural criticism-criticism, that is, of the excessively Baroque culture that was clearly at odds with the lived experience of the non-courtly population- that found an outlet in this generic focus on the force of deception. ${ }^{1}$

It is from this point of the current scholarly debate that the present article takes off and presents Restoration epistolary culture as implicated in a discussion that is intimately tied to new forms of gendered corporeality. The letter as a literary form of representation allowed both readers and writers to reflect on the mediated nature of writing; and it invited a form of reception that grew increasingly aware of the tenuous relationship between sign and reality. The larger implications of this realisation were tested in early modern literary culture's slightly sceptical stance towards epistolary forms of communication. By looking at two textual sites of Restoration epistolarity, John Dunton's Athenian Mercury and Peter Motteux's the Gentleman's Journal, the present article demonstrates how letters in these two periodicals deployed the full range of generic possibilities resulting from the letter's mediated and disembodied form of communication both as a means for engaging

\footnotetext{
${ }^{1}$ How early modern epistolarity is frequently used for deceptive purposes is discussed in Schneider, "Politics, Deception"; and Bayer, "Deceptive Narratives."
} 
in various forms of gender performativity and, simultaneously, as an instance of textual self-reflection about the implications of textual representation.

\section{FLEA-ING IDENTITIES}

While the Athenian Mercury (1691-1697) may not be the first periodical to emerge from the lively literary ecosystem of the late seventeenth century, it is regarded as one of those having helped pave the way for and shape the Age of Periodicals and its main players such as the Tatler and the Spectator in the following century. Published and edited by John Dunton and his Athenian Society, a semi-fictional group of experts modelled on the Royal Society, the periodical tackled topics ranging from natural philosophy, medicine, divinity and mathematics to domestic matters, courtship advice and questions of love. Concerning form, the Mercury's unique selling point was "to endeavour the Answering any reasonable Question which should be proposed" to the editorial board, as "the first and most natural way to obtain [...] Knowledg, is by Questions and Answers" (Vol. 1, Preface). Questions were to be sent via "a Penny Post Letter to Mr. Smith at his Coffee-house [...], where orders are given for the Reception of such Letters" (Vol. 1, No. 1). Thus, from its very first issue, the Mercury made readers' contributions an essential part of its concept. In order to disinhibit the ensuing debate, "to remove those Difficulties and Dissatisfactions, that shame or fear of appearing ridiculous by asking Questions, may cause several Persons to labour under," the submissions were to be printed anonymously. Participatory elements such as these enabled not only the Athenian Mercury, but the periodical as such "to collect and define a new audience, to project an image of a community of readers mutually engaged in the production of the text" (Shevelow 38). One of the Mercury's explicit goals for dealing with its own "community of readers" was to include and make visible its female readers -in its own words, "to answer all manner of Questions sent us by either Sex" (Vol. 1, No. 13).

As it happens, this proclamation of the Athenian Society should not prove mere lip service. A significant amount of space in Dunton's periodical is dedicated to interactions between women and men and questions situated in an "area of social experience [marked] as 'feminine' in implicit distinction from the other forms of experience represented which, by implication, are 'masculine"' (Shevelow 71). In her seminal study Women and Print Culture, Kathryn Shevelow argues that "[t]he periodicals' characteristic attention to women and 'women's concerns' [...] served an emerging ideology that, in the act of making claims for women's capabilities and social importance, constructed women as essentially -that is, both biologically and socially- 'other' than men" (1). Thus, while the Athenian Mercury can be regularly observed to stand up for women's concerns, female correspondents were often depicted as dependent on the all-male editorial board's guidance, effectively situating the periodical in the vicinity of the conduct book regulating female behaviour and relegating women to a space identified as 'private' as opposed to the 'public' area of men (Shevelow 4). The Mercury's answers, therefore, reveal a rather heterogeneous perception of 'women' and 'men' fluctuating between proto-feminist 
egalitarianism and misogynistic condescension. Women are mostly represented as intellectually equal, emotionally superior yet passive beings, dependant but at the same time responsible for the nation's moral well-being. Men are depicted as the active yet also aggressive part -be it during courtship, in business or in their day-today interactions with women in need of their sympathy and advice. ${ }^{2}$ Shevelow points out these representational discrepancies as well as the regulatory practices of the Athenian Mercury and its successors; however, she maintains that "the construction of femininity in writing helped to encode a form of feminine authority that defined -that is, both enabled and delimited-a place for women in print culture" (15).

While Shawn Lisa Maurer concurs with many of Shevelow's observations, she emphasises the fact that numerous studies of the Athenian Mercury and its fellow periodicals have focused too narrowly on representations of femininity and consequently neglected the production of a corresponding masculinity. In her study Proposing Men, Maurer problematises the notion of separate spheres that has been investigated by critics such as Shevelow (focusing on the private, following Nancy Armstrong) and Terry Eagleton (directing his attention to the public, following Habermas) without fully considering the extent to which periodicals produced and simultaneously naturalised the boundaries between "public and private, masculine and feminine" (19). A closer examination, Maurer argues, reveals the interplay and mutual dependence of those spheres, with the figure of the family man, acting both publicly and privately, from the very start permeating the apparently exclusively feminine domestic sphere (20). This “'sentimental masculinity, in which the so-called private space of the home supplanted the polis as a locus for masculine virtue" (7), propagated the ideal of a chaste patriarch closely monitoring his family in contrast to that of the licentious rake (75). The chaste patriarch, however, could only be such by acting out "potentially dangerous sexual and economic appetites" within the sanctioned framework of marriage, whereby at the same time he is posited as a desiring subject and his wife or women in general as desirable objects (75).

Since Shevelow and Maurer, among others like E.J. Clery and Helen Berry, for example, broached the topic of gender relations in their analyses of the Athenian Mercury, many of the ensuing readings have, in one way or another, portrayed a rather passive femininity. Of course, this is rooted to a considerable degree in the source material. Despite defending women and their capabilities as well as providing them with a platform to articulate their experiences, the Athenian Mercury clearly perpetuates a patriarchal perspective on the roles and duties of eighteenth-century men and women. Yet, there seems to be a burgeoning trend to address more active

2 This observation does not only apply to Dunton's periodical. According to Shevelow, this heterogeneity was part of the periodical landscape from its inception. She notes, however, that early periodicals such as the Gentleman's Journal or the Athenian Mercury still retained a "relative openness" which "in fact, permitted them occasionally to articulate the rationalist feminist arguments which were current in the later seventeenth century" in contrast to their immediate successors like the Tatler, the Spectator or the Guardian, which moved in a more rigid ideological framework, more clearly limiting female agency (50). 
and thereby more overtly 'problematic' depictions of femininity that destabilise constructions of masculinity. In a recent essay, Nicola Parsons offers a reading of various queries in the Ladies Mercury, a possible spin-off of its Athenian namesake, ${ }^{3}$ focusing on the space the Ladies Mercury provides for relations of female "sexual experience" (321). In a similar vein, Slaney Chadwick Ross explores the theme of "sexual enjoyment" in the Ladies Mercury (336). While these recent analyses mainly concentrate on the Ladies Mercury, there are still parts of the Athenian Mercury that remain uncharted.

\section{FLEA BITES}

One hitherto disregarded passage found in Dunton's periodical manages not only to foreground a dominant, almost dangerous femininity, but at the same time to invoke a curiously submissive masculinity and even to destabilise established gender roles altogether when it starts to conflate 'male' and 'female.' The passage in question starts off with the seemingly innocent query: "Whether Fleas have stings, or whether they only suck or bite, when they draw Blood from the Body?" (Vol. 1, No. 17). Right at the beginning of the corresponding answer, the 'querist' -the term used by the Athenian Mercury to refer to their correspondents- is identified as female, being addressed as "Madam!" by the editorial board. Accordingly, the answer starts with the typically good-natured condescension the Athenian Society tends to employ when answering women's queries on proto-scientific topics, signifying that the ladies are entering unknown terrain: "Not to trouble you, Madam! with the Hebrew or Arabick Name of a Flea, or to transcribe Bochart's learned Dissertations on the little Animal." On the one hand, the Mercury hereby implies that the female proportion of its audience does neither speak Hebrew nor Arabic ${ }^{4}$ and similarly is not acquainted with Samuel Bochart's research on the flea -or that it is not even interested in this sort of information (which may be interpreted as the bigger slight due to the immense importance the Mercury places on the concept of 'curiosity' throughout its entire run). Furthermore, the word 'trouble' denotes the knowledge withheld by the Mercury as something unpleasant, something inconvenient that must be kept away from the ladies.

The Mercury's reluctance to trouble its female readers with unnecessary information could, on the other hand, be interpreted as a way of actually facilitating the access to knowledge by removing barriers such as foreign languages and longwinded deliberations loaded with technical terms. Instead, the editors promise to

${ }^{3}$ As of now the authorship of the Ladies Mercury has not been conclusively clarified. Propositions range from "the Mercury [...] may have generated the companion publication" (Shevelow 64), through "usually attributed to Dunton" (Maurer 54), to "Dunton ventured to publish a separate Ladies Mercury under the pseudonym of 'T. Pratt'” (Berry 23).

${ }^{4}$ Not that the bulk of their male audience could do so either, yet statements such as these are generally directed at querists perceived as female. 
"give such a Description thereof, as we have yet been able to discover," relating the desired information in their own words and from their own experience for the lady's "satisfaction." After these initial remarks, the Mercury starts describing the flea:

It is, as we may partly discern by the naked Eye, of a lovely deep Red colour, most neatly polish'd, and arm'd with Scales, which can resist any thing but Fate and your Ladiships unmerciful Fingers; [...] it has two Eyes on either side of its Head, so pretty, that I'd preferr 'em, to any, Madam, but yours, and which it makes use of to avoid its Fate, and fly its Enemies, with as much nimbleness and success as your Sex manage those fatal Weapons (lovely Basilisks as you are) for the Ruine of your Adorers. Nature has provided it six substantial Legs, of a great strength, and incomparable agility, [...] and armed each of 'em with two Claws, which appear of a horny substance, more sharp than Lancets, or the finest Needle you have in all your Needle-Book-'Twas a long while before we cou'd discover its Mouth, which we confess we han't yet so exactly done as we wou'd, the little bashful Creature always holding up its two fore-feet before it, which it uses instead of a Fan or Mask when't has no mind to be known ${ }^{5}$

What immediately strikes the reader's eye is the flattering way in which the flea is portrayed, sporting such distinguishing features as a "lovely deep Red colour" and being "neatly polish" $d$ " reminiscent of precious jewellery; when it comes to its eyes, they are depicted as "so pretty, that I'd preferr 'em, to any, Madam, but yours." It is at this point, that the Mercury starts comparing the flea directly to the lady in question, preferring the lustre of its eye to everyone else's -presumably including all other women, subordinating them to the flea- but the querist's very own. The comparison does not stop here, for the flea uses its eyes "to avoid its Fate, and fly its Enemies, with as much nimbleness and success as your Sex manage those fatal Weapons (lovely Basilisks as you are) for the Ruine of your Adorers" and owns claws which in their sharpness resemble "the finest Needle you have in all your NeedleBook." Last but not least, "the little bashful Creature['s]" legs correspond to "a Fan or Mask" that it can hold up "when't has no mind to be known." The Mercury hereby attributes the quality of bashfulness to the animal, also referring to it as "this modest one" later on, one of the traits usually reserved to define the ideal woman, as can be seen in the Mercury's answer to the request for a prayer to secure the perfect wife in another issue, for example. ${ }^{6}$ This is furthermore reinforced by the reference to fan and mask. A link is established between the lady and the flea, with the connection

5 Here, the Mercury's account echoes Robert Hooke's observations on the flea in Micrographia (1665), where he notes the creature's "beauty," describing its scaly armour, its head "beautify'd with a quick and round black eye," its legs and trunk. The trunk and the tongue, he notes, "lye covert between the fore-legs," just as the Mercury does several decades later $(210,211)$. What Hooke's description does not provide, however, is the connection between flea and femininity.

6 The editors advise the male querist in question to pray for "One to whom Nature has been liberal in good Features and Proportions of Body, but yet with a fairer Mind, Witty without Abuses, Modest without Weakness, [...]. [...] Whose Virtue, Wit and Modesty can rather be imitated than equal'd by her Neighbours" (Vol. 2, No. 16). 
working both ways: on the one hand, the flea is anthropomorphised and feminised, receiving the features of a lady. On the other hand, the lady is animalised, denigrated by the comparison to the flea, a creature usually perceived as an unwelcome parasite associated with a lack of personal hygiene craving its host's blood.

Yet, the figure of the lady is not exclusively realised in comparison to the flea. Despite being implicitly equated with the bloodthirsty insect, the lady furthermore emerges as a separate entity when addressed by the editorial board in its answer. However, in contrast to the conventional modest femininity represented by the bashful hematophage, the female querist's depiction resonates with dominance, cruelness and violence. As the reader learns, the animal is "arm'd with Scales, which can resist any thing but Fate and your Ladiships unmerciful Fingers," which insinuates that the lady would mercilessly crush the little insect as soon as she were able to lay her hands on it, while the only other force capable of harming the flea is fate itself, which ascribes a considerable amount of power to said lady. This connection to fate is emphasised when the Mercury refers to the flea's eyes, "which it makes use of to avoid its Fate, and fly its Enemies" -hereby designating the lady as an enemyusing them "with as much nimbleness and success as your Sex manage those fatal Weapons (lovely Basilisks as you are) for the Ruine of your Adorers." During the course of this sentence, the editors move from referring to the querist in particular to the female sex as a whole, brandishing their eyes, "those fatal Weapons," with "nimbleness and success" -indicating a repeated use and a subsequent familiarity with the act. According to the Mercury, these weapons are specifically used "for the Ruine of your Adorers," who are presumably male and utterly at the females' mercy, a fact which is underlined by referring to women as "lovely Basilisks," further animalising them and attributing almost supernatural powers to their gaze, which enables them to turn helpless suitors into stone.

It is not only the lady's potential suitors who fall prey to her influence; not even the Athenian Mercury's unwavering editors can resist granting her desires. In order to "discover its Mouth" and thereby to answer the lady's question, the Athenians "were forced to be guilty of an Act both uncivil and cruel, without which we cou'd never have given you a Resolution to your Question": namely, they "were obliged to unmask this modest one, and cut off the two Legs on't to come to the Face." This "being perform'd (tho' it makes our tender Hearts, as well as yours, almost bleed to think on't)," they continue, "we immediately discovered what your Ladyship desired." Writing that they were "forced" as well as "obliged" to dissect the insect, the impression is created that the mutilation of the flea is not something the Athenians would have done without the express wish of their querist and that they are acting against their will.

To proceed with the deed is depicted as the only option to resolve her question and thereby to satisfy her desires. The fact that the execution of the act, described as "both uncivil and cruel," is prompted by the lady, making the editors feel "guilty" and their "tender Hearts [...] almost bleed to think on't," implicitly transfers the qualities of uncivility and cruelty to the querist, situating her in a different moral environment from the one the Athenians inhabit. Remarking that taking apart the flea is bound to make the Athenians' hearts bleed "as well as yours," i.e. the female 
querist's, appears almost ironic under these circumstances. Alternatively, this remark may also be regarded as an appeal to the querist to mend her ways, prompting her to empathise with the animal. This comment could therefore be read as an instance of Maurer's 'sentimental masculinity,' with the male editorial board basically telling the querist how and what to feel, encroaching on the supposedly private, female domain of emotions, implicitly regulating her behaviour. Irrespective of the Mercury's intentions, its compassion and emotional reaction to harming the little animal places it on the side of the feminised and meek flea in opposition to the implicitly crueller female correspondent.

Assuming that the insect is indeed assigned feminine characteristics, its dissection as well as the respective result are put into a somewhat dubious light. In order to expose the animal's "Face" along with its "Mouth," the all-male editorial board has to forcefully remove the fore-feet it uses like a fan or mask. Lurking behind the lady-like exterior, however, is

a strong Proboscis or Trunk, as a Gnat or Muschetto, tho' much Thicker and Shorter, with which we may very well suppose it penetrates your fair Hand, feasts it self on the Nectar of your Blood, and then like a little faithless Fugitive of a Lover, skips away almost invisibly, no body knows whither.

The previously feminized flea hereby acquires features of a masculine corporeality, namely: a penis. Determining "[w] hether Fleas have stings, or whether they only suck or bite" turns into determining the flea's sex. And that is not as conclusive as one would think. The phallic imagery of the thick trunk is further enlarged upon by referring to the act of penetration of the lady's hand. Linking the flea's proboscis to the phallus almost automatically invokes the association of the mouth hidden behind the fan with the vagina. Removing the protective feet could therefore be read as an attempted way of deflowering the hematophage -with a somewhat sobering outcome. Apart from being endowed with a penetrating trunk, it displays another stereotypically masculine -a more specifically rakish- trait: the parasite "feasts it self on the Nectar of your Blood, and then like a little faithless Fugitive of a Lover, skips away almost invisibly, no body knows whither." Explicitly comparing the animal to a lover fleeing the scene after feasting itself on the lady's nectar posits the sucking of her blood as a not-so-subtle cipher for sexual intercourse and the flea itself once more as a man. Contemporary readers might already have encountered a similar connection in John Donne's "The Flea" (1633), where the mingling of a woman's and a man's blood inside a flea that bit both of them stands for a sexual union. The Athenian Mercury hereby situates itself within a literary tradition established long before Donne's text. Apart from Aristotle's and Pliny's views on the procreation of fleas, "[ $t$ ]here was a long tradition of flea poems in Latin, English, French, [and] Arabic" (Brumble 148). One of these, "Carmen de Pulice," a poem falsely attributed to Ovid, "had inspired so many imitations in this period that by 1582 , [...] an anthology quoting 50 flea poems had been published in France by Étienne Pasquier, in each of which the lover envies the parasite's right to nestle in the lady's bosom and to 'taste' the joys of her flesh" (Roston 91). Interpreting the 
flea as masculine thus allows for yet another reading of the Mercury's answer. The flea appears to be "of a lovely deep red colour, most neatly polish'd" to the "naked Eye" only; on second glance, it emerges as a male locked in deadly combat with the "Ladiships unmerciful Fingers."

In connection to the uncertainty surrounding the insect's gender, the Athenian Mercury's reception history might hint at a final way of handling the flea question. Almost all scholars dealing with Dunton's periodical have at some point to tackle the question of authenticity in their own research. Countless commentators, partly prompted by the Mercury's contemporaries, have grappled with the unreliability of the Athenian Society's proclamations -for the simple reason that the society itself was at least partly a hoax, consisting of far fewer members who furthermore pursued other employments than those proclaimed by the Mercury and other publications of Dunton (Parks 75). Another problem is posed by the queries themselves. In Helen Berry's words:

One of the questions that strikes most people when they see a copy of the Athenian Mercury for the first time is: were any of the questions in the text real? Some contemporaries in the 1690s were no less sceptical than today, and raised doubts at the time as to whether the periodical was truly representing readers' letters in print. (35)

During its seven-year run the Athenian Mercury frequently addressed questions of authenticity itself, sometimes warding off attacks on its reliability and sometimes questioning the truth value of its readers' statements. Questions about its readers' gender constitute one recurring area of conflict. In one issue, one querist asking for advice on how to choose between two gentlemen, after briefly introducing them, closes her (?) question with: "I desire to know how far Ovid's Rule must take place? -Sed vitate Viros cultum, formamque professos, Quique suas ponunt in statione comas." Convinced that they are being tricked, the Athenians immediately pounce on their reader: "O Sir! or Madam! chuse you whether -Your Hee-Ladiship has forgot that Women don't use to Cap Verses, especially in Latin, any more than our Lady ought to have spoke in the Church, when she saluted St. Bernard" (Vol. 9, No. 26). In yet another issue, they reply to a "pretended Cookmaid," addressing

7 Taken from Ovid's Ars amatoria (3.433-3.434), said rule cautions against the fickleness of certain men: "But stay away from men with pretensions to grooming and beauty, / and those who carefully put their hair in order" (Ovid 154). Following this, the passage continues by advising women to stay away from this type of man on account of the effeminacy signalled by such an exaggerated attention to one's appearance: "What's a woman to do when the man is smoother than she / and, perhaps, could have had a greater number of men? / [...] Don't let their hair deceive you, slick and gleaming with perfume, / or the short shoe-strap folded into its creases; / don't let the toga of finest thread take you in, or if / there's one ring after another upon their fingers: / it may be that the most refined of all from that crowd / is a thief, and is burning with passion -for your clothes!" (154). The effeminate cross-dresser's desire for a woman's clothes (and a lack thereof for herself) resonates fittingly with the Mercury's accusing answer. 
them as "Thou He-Cookmaid" (Vol. 10, No. 3). On one occasion, they are explicitly queried about "how you come to have the Art of discerning, and to distinguish a Male Query from a Female; wherein too we doubt you are oftentimes mistaken." What the Athenians, by their own account, do, is "guess by the Hand, the Stile, and the Querists own Subscription and Affirmation, which we are sure never fails unless some Roguy Male Querist paulms upon us in the other Sexes name," deconstructing their own way of ascertaining their querists' gender as they go (Vol. 9, No. 15). Bringing this background to the analysis of the flea query, an additional metatextual reading becomes possible. Along with the dubious position of the flea as both man and woman complete with fan and mask, the multiple references to unmasking, hiding "when't has no mind to be known," its first appearance to "the naked Eye" and the pervading ironic undertone, the Mercury's entire answer could be interpreted as an elaborate way of exposing a supposedly female querist as a male cross-dresser in textual drag.

Simultaneously incorporating masculine and feminine traits, the unassuming insect consequently emerges as a hermaphroditic being which destabilises gender roles, combining a pretty, meek and feminine exterior with a hidden masculine sexuality. Usually part of an aggressive masculinity, the corresponding behaviour is outsourced to the female querist by the Athenians, expressing itself in an unladylike propensity for violence and dominance. This is not to say that the Athenian Mercury automatically endorses overly subversive concepts of femininity. While the lady's projected behaviour is not explicitly censored, the editors' playful, mocking tone at all times hints at their regulatory function. In contrast, the stereotypical feminine meekness partly attributed to the bashful flea is acted out by the editorial board in turn, staging themselves as empathic victims fatally attracted to the lady's desire for knowledge. The image of the flea constructed by the Mercury's answer is thereby almost grossly overdetermined, overburdened with semantic energy like an actual flea gorged with blood to the point of bursting.

\section{REVERSING GENDERED LETTERS}

What happens when a gendered play on epistolary identity actually does burst is evoked in one of the short narrative prose fictions that appeared in each issue of the Gentleman's Journal, the periodical produced by Peter Motteux in the early 1690s in the shape of a monthly letter written from the urban centre of London to its readers living in various provinces across the British Isles. Motteux filled his issues with a wide array of different text types, including straightforward news and reports about public events with scholarly essays about natural phenomena alongside purely entertaining elements from various aesthetic traditions covering poetry, sheet music and also short stories, creating an early example of a commercially successful periodical (Ezell). Most of these short stories are built around social comedy or matters of amorous conquest and thus fit perfectly the Restoration interest in what the stage cultivated as Restoration comedies. In these stories, letters mostly feature as direct forms of communication that transport information across spatial distance, 
usually relying on truthfulness in both the identity of the sender (and recipient) as well as the content transported. The veracity at stake in Restoration epistolarity forms part of the complex problematisation of truth that Michael McKeon has accurately presented as a crucial factor contributing to the rise of the novel, and that Sonia Villegas López has studied in various examples from Restoration fiction. As if to confirm this claim and extend it to the context of periodical forms of textual selffashioning, on a number of occasions Motteux includes epistolary encounters that draw on the format of the letter in order to put into play those very assumptions about veracity and identity. Just as Dunton's description of the flea invites readers to question the assumed gender identity of the magazine's contributors (and the actual existence of its experts), so Motteux's use of epistolarity undermines the assumption of reliability conventionally assigned to the format of the letter.

This aspect of his employment of epistolarity as a tool for questioning gendered identities is one of the central textual features in the short story called "The Nobel Statuary," which appeared in the January issue of 1691/92. At the very outset of this text about a stonecutter's pursuit of his noble beloved, the narrator directly addresses his readers to inform them that the display of emotions as frequently encountered in moments of extreme excitement are not to be fully trusted as they habitually present a front to the world that is highly staged and borders on the theatrical. ${ }^{8}$ The story begins by confronting its readers with the experience of mourning:

Amidst the daily instances, we have of the unfeigned grief, which disconsolate Widows express for the loss of their beloved Consorts, it ought not to be wondred at, why those that judge of things by their exterior, are as subject to mistake an affected sorrow for a real grief, as our Cullies, the fawnings of their Misses for a true Passion. (37)

This opening passage introduces a number of themes that are highly relevant for the gender politics of Restoration epistolarity. By addressing the tricky coexistence of "affected sorrow" and "real grief" the text stresses that even the embodied presentation of extreme emotions are not always to be trusted by those who encounter them. The text immediately goes on to compare this type of duplicity to the field of romance and wooing when it brings in the easily duped "Cullies" and their misjudgement of their lovers' bodily responses. In sexualizing the manner in which communication is prone to mislead its recipients, the opening passage sets the tone for the subsequent manipulation of its protagonists as they engage in various forms of personal but also impersonal communication in the form of letters.

The stone cutter is introduced as a mixture of virile masculinity and somewhat naïve amorous enthusiasm, whose rhetorical abilities are clearly at odds with the Restoration fashion for wit and literacy:

\footnotetext{
${ }^{8}$ See Peters for a discussion of how letters were incorporated into dramatic forms at the time.
} 
He that was sent for, chanced to be one of those Fellows who by a small stock of Memory, and a great one of Confidence, a Magazine of Puns and Clinches [sic], a Talent in the noble modern art of bantering, and such like stuff, as is by some in the Country miscalled Wit, had gained the name of a boon Companion, a set up for Top-wit of the No-wits of the Town; and though he could not read, and therefore had neither plundered Vitruvius nor Columella, nor could challenge a Precedency with Michael Angelo, or a Cavalier Bernini, yet was a good second or third rate Stone cutter, Carver, or Statuary, as you will have it. (38-39)

The text's referencing of canonical artists and artworks, flattering as it does the cultural competence of the magazine's readers, places the artisan at an educational level below that of his immediate environment. His illiteracy, however, is seen as a welcome occasion to allow for epistolarity to replace more direct and thus revealing forms of communication.

While the plot builds towards the writing of rather explicit and deceitful letters, the two lovers initially meet in person, and the excessive physicality of their mutual admiration sets the tone for the excessive form of distant communication that will develop once the complications surrounding their love plot set in. As the newly widowed lady encounters her future lover, her reaction is described in precisely the terms of dissimulation and deception with which the short story had opened, and to which the moment of epistolarity will soon add its own kind of generic resonance:

It seems he nick'd the critical minute, for he no sooner appear'd, but like a Sun, he drove away the Clouds that hanged over the fair Hippolita's heart, and kindled there a flame too prevalent to be remov'd afterwards by all the weak resolves of Pride and Reason. She nevertheless call'd her dissimulation to her relief, and checking her too easy heart, hid her disorder as well as she could, yet not so well, but that our Man of Stone discover'd it, or at least imagined so. (39)

As the kindled flame of her desire leads to "dissimulation" and a form of "disorder," her attempt at hiding the manner in which his presence affects her fails precisely because her physical reaction is betrayed through the very affectedness of her demeanour. Since they are meeting in person, corporeal forms of meaning-making add to the much more easily dissimulated forms of mere linguistic sign-making.

Returning to the theme addressed at the beginning of the tale, of the habitual distance between reality and its textual representation, the narrative later provides its readers with information that demonstrates that what they are reading is a mere fraction of what was actually played out in reality, emphasizing that writers edit, shorten and, possibly, also alter what they present: "To tell you all she said, and what our officious Stonecutter preach'd to her, would swell my Novel to the bulk of a Folio, and that would be the way to have you take it for a Romance" (40). The explicit evocation of generic conventions -the references to the forms of the "Novel" and its rival, the "Romance"- and the materiality of the print object -here in the shape of the much more illustrious form of the "Folio"-address the very principle of paratextuality and generic expectations that readers use when they place particular texts into conventions and forms of knowledge they already know, 
or at least assume they know. ${ }^{9}$ That such predispositions are frequently misdirected is one of the themes presented to the readers.

As the stonecutter prepares his suit to his beloved, he loses confidence in the powers of persuasion he may put into a letter written by his own hand, so he solicits support from his fellow members at a club. In the end, this most intimate of letters, one that woos the woman he loves, ends up being an allographic epistle, penned by a third party not directly involved in the amorous exchange between the two lovers. The narrative openly addresses the fact that there are various players and their respective desires that contribute to this development of an intimate letter becoming a scene of deception when it states that "To that end he desire'd one of the Club to write a Letter for him" (44): by explicitly referring to the fact that the letter was written with a particular "end" in mind, namely to press his case with the lady, it furthermore shifts the balance from a purely emotional outflow of personal feelings to a calculated missive to create a wished-for outcome. The letter, or so readers are invited to ponder, is a form of communication that is mostly constructed for the effect it may create; and in the process of this fabrication of results it permits elements of manipulation. What makes the present case of a deceitful letter even more fascinating is the fact that the stonecutter, being illiterate, has to trust his chosen ghost-writer when it comes to the content of the text, a trust that the readers find is not well placed: "The Gentleman, to divert himself and the rest, fram'd him the following Epistle, all in his own Cant, which when he had read to him quite differently, was by our Lover sent to his Mistress" (44). The actual letter, which addresses the lady in rather confrontational tones and includes a few somewhat witty remarks about the physicality of a stone-cutter's talents in the arena of romance, begins with these words: "Were you not harder than Pophiry or Agath, the Chizel of my Love, drove by the Mallet of my Fidelity, would have made some impression of your Heart" (44). The letter, addressing the lady as "Divine Flint" and making use of some highly allusive phallic metaphors, is clearly meant to embarrass its supposed author, the illiterate stone cutter, crudely evoking gendered clichés about romance and desire.

Yet the narrative at this point surprises readers' expectations in that it presents the lady's attitude as one that does not fall within the confines of ladylike romantic epistolarity. Rather than turning away in horror at the incivility expressed in the letter, she instead pursues her initial interest in the stone cutter despite the tone and content of the (allographic) missive. And to make sure that readers in fact take notice of this break in decorum, ${ }^{10}$ the text actively addresses how this particular exchange of letters constitutes a departure from generic conventions:

Now you expect that I will tell you that she scornfully tore his Letter, and sent him some damn'd cross message, such as to slit his windpipe with his Chizel, or dash out his brains with his Mallet; but it happened quite contrary, Love was his

9 For a discussion of early forms of criticism, see Gavin; and for the generic self-fashioning of Restoration prose narratives, see Bayer, Novel Horizons.

${ }^{10}$ On decorum in Restoration espitolarity, see also chapter 5 in Barnes. 
Advocate, she put a favourable construction on every thing, and sent him word to use all the means imaginable to be made a Knight, and expect to find her kind, assuring him that a Bill of Exclusion was passed on all but him, from any pretences to her Person; he had like to have leapt out of his Skin for joy, and have broke his neck for haste to give an account of this to his Cronies of the Club [...]. (46)

This passage is remarkable for a number of reasons: it begins by explicitly admitting to the existence of readers' expectations ("you expect"), suggesting that the rudeness of the letter could not but have disturbed the recipient and that she would therefore respond in kind, effectively ending the romance before it could go any further. Tellingly, the violence that is evoked here affects both the supposed author of the letter (who is advised to kill himself) and the letter itself, which the conjecture assumes she would have wanted to "tore." Instead, the relationship is allowed to continue on a positive path, not without the narrator claiming that the narrative accurately reports what actually "happened," addressing the very reliability on the trustworthiness of an impersonal communication (this time between actual author and real-world reader) that the letter which forms the occasion for this observation has just so gratuitously flaunted. To explain why this particular plot should develop along such unexpected lines, the text points to the combined effects of romance and semantics: driven by "Love," his beloved "put a favourable construction on every thing," meaning that out of the blindness that goes with an inflamed heart the mind will construct meaning out of phrases that run counter to their actual intention and proper semantic context.

What the letters in "The Nobel Statuary" thus reveal is a fascinating interest, within Restoration literary culture, in the pliability of epistolary communication, in particular when it comes to the shaping and making of gendered identities. The letter, unlike the personal face-to-face conversation, allows for the kind of posturing and self-fashioning that gained importance during the tumultuous years of the waning seventeenth century. At the same time, however, it acts as a reminder to readers that textual intention always exists at the risk of being misread or even reversed, as when the widow simply refuses to be insulted and instead reads the letter in the light of the corporeal meeting with the stone cutter that preceded the written communication.

\section{SIGNED “TRULY YOURS”?}

As the two examples discussed above indicate, Restoration readers would at least occasionally encounter epistolary moments of communication that interrogated the identities of their respective writers, including their gender. They met with such instances of faked letters in various contexts: some invited them to read the genre of the letter as a mixing of instances of truth-telling with the much more selfcritical notion of how impersonal forms of communication evoke deceptive forms of address. When epistolarity occurred in such contexts, it allowed for forms of misrepresentation that resulted precisely from the very absence of the speaking body as a means of verifying (or otherwise) what the speaker says. What Elizabeth Heckendorn 
Cook discusses as the complex "construction and definition" of eighteenth-century corporealities through the flexibility found in epistolary forms of communication thus also plays a significant role in the Restoration periodicals discussed here.

Reviews sent to authors: 15 July 2019

Revised paper accepted for publication: 16 August 2019 


\section{WORKS CITED}

Barnes, Diana G. Epistolary Community in Print, 1580-1664. Ashgate, 2013.

BAYER, Gerd. "Deceptive Narratives: On Truth and the Epistolary Voice." LiLi: Zeitschrift für Literaturwissenschaft und Linguistik 39.154 (2009): 362-77.

Bayer, Gerd. Novel Horizons: The Genre Making of Restoration Fiction. Manchester UP, 2016.

Beebee, Thomas O. Epistolary Fiction in Europe 1500-1850. Cambridge UP, 1999.

Berry, Helen. Gender, Society and Print Culture in Late-Stuart England: The Cultural World of the Athenian Mercury. Ashgate, 2003.

Bray, Joe. The Epistolary Novel: Representations of Consciousness. Routledge, 2003.

Brumble, H. David III. “John Donne's 'The Flea'. Some Implications of the Encyclopedic and Poetic Flea Traditions.” Critical Quarterly 15.2 (1973): 147-54.

Chadwick Ross, Slaney. “John Dunton's Ladies Mercury and the Eighteenth-Century Female Subject." Women's Periodicals and Print Culture in Britain, 1690-1820s. Ed. Jennie Batchelor and Manushag N. Powell. Edinburgh UP, 2018. 327-341.

Clery, E.J. The Feminization Debate in Eighteenth-Century England: Literature, Commerce, and Luxury. Palgrave, 2004.

Соок, Elizabeth Heckendorn. Epistolary Bodies: Gender and Genre in the Eighteenth-Century Republic of Letters. Stanford UP, 1996.

DAY, Robert Adams. Told in Letters: Epistolary Fiction before Richardson. U of Michigan P, 1966.

Ellis, Markman. The Coffee-House: A Cultural History. Weidenfeld \& Nicolson, 2004.

Ezell, Margaret J.M. "The Gentleman's Journal and the Commercialization of Restoration Coterie Literary Practices.” Modern Philology 89.3 (1992): 323-340.

Gavin, Michael. The Invention of English Criticism, 1650-1760. Cambridge UP, 2015.

Hooke, Robert. Micrographia. Or Some Physiological Descriptions of Minute Bodies Made by Magnifying Glasses with Observations and Inquiries Made Thereupon. John Martyn, 1665.

Loveman, Kate. Reading Fictions, 1660-1740. Ashgate, 2008.

Maurer, Shawn Lisa. Proposing Men. Dialectics of Gender and Class in the Eighteenth-Century Periodical. Stanford UP, 1998.

McKeon, Michael. The Origins of the English Novel, 1600-1740. Johns Hopkins UP, 2002.

O'NeILl, Lindsay. The Opened Letter: Networking in the Early Modern British World. U of Pennsylvania P, 2015.

Ovid, and Julia Dyson Hejduk. The Offense of Love. Ars Amatoria, Remedia Amoris, and Tristia 2. U of Wisconsin P, 2014.

Parks, Stephen. John Dunton and the English Book Trade: A Study of His Career with a Checklist of His Publications. Garland, 1976.

Parsons, Nicola. “The Ladies Mercury." Women's Periodicals and Print Culture in Britain, 16901820s. Ed. Jennie Batchelor and Manushag N. Powell. Edinburgh UP, 2018. 315-326.

Peters, Susanne. Briefe im Theater: Erscheinungsformen und Funktionswandel schriftlicher Kommunikation im englischen Drama von der Shakespeare-Zeit zur Gegenwart. Winter, 2003. 
Raymond, Joad. The Invention of the Newspaper: English Newsbooks, 1641-1649. Clarendon-Oxford UP, 1996.

Roston, Murray. The Comic Mode in English Literature: From the Middle Ages to Today. Continuum, 2011.

Shevelow, Kathryn. Women and Print Culture. The Construction of Femininity in the Early Periodical. Routledge, 1989.

Schmidgen, Wolfram. Exquisite Mixture: The Virtues of Impurity in Early Modern England. U of Pennsylvania P, 2012.

Schneider, Gary. "Politics, Deception, and the Workings of the Post: Some Features of Epistolarity in Early Modern England.” Explorations in Renaissance Culture 28.1 (2002): 99-127.

SCHNeIder, Gary. The Culture of Epistolarity: Vernacular Letters and Letter Writing in Early Modern England, 1500-1700. U of Delaware P, 2005.

Schwoerer, Lois G. The Ingenious Mr. Henry Clare, Restoration Publicist. Johns Hopkins UP, 2001

Singer, Godfrey Frank. The Epistolary Novel: Its Origin, Development, Decline, and Residual Influence. U of Pennsylvania P, 1933.

The Athenian Mercury, or Casuistical Gazette, ed. John Dunton. London, 1691-1697.

The Gentleman's Journal; Or, The Monthly Miscellany, ed. Peter Motteux. London, 1692-1694.

Villegas López, Sonia. "Narratives of Truth-Telling in the Making of the English Novel: William Congreve's Incognita and Mary Pix's The Inhumane Cardinal.” The Female Wits. Ed. Pilar Cuder Domínguez, Juan Antonio Prieto Pablos, and Zenón Luis Martínez. Servicio de Publicaciones de la Universidad de Huelva, 2006. 207-229.

Whyman, Susan E. The Pen and the People: English Letter Writers, 1660-1800. Oxford UP, 2009. 
